\title{
Correspondence
}

\section{The difficult airway}

To the Editor:

With respect to the management of the difficult airway, ${ }^{1}$ I have two further suggestions for optimal visualization of the larynx. Often when the larynx is anterior, all that is needed to improve the view is to displace the larynx to the left and turn the patient's head to the right. This has the immediate effect of lining up the airway with the curve of the endotracheal tube as it is introduced from the right corner of the mouth.

When visualization is more difficult, a standard laryngoscope can be combined with a lighted stylet. The added light works wonders; especially for those of us whose visual acuity is deteriorating with age. The stylet is useful for directing the tip of the tube and the light can be seen from outside to be in the correct position before the end tidal $\mathrm{CO}_{2}$ line is connected and before the first positive pressure breath is given.

\section{Graham MD FRCPC}

Vancouver, B.C.

\section{REFERENCE}

1 Crosby ET, Cooper RM, Douglas MJ, et al. The unanticipated difficult airway with recommendations for management. Can J Anaesth 1998; 45: 757-76.

\section{REPLY:}

Dr. Grabam's letter emphasizes one point made in our paper and introduces a second important topic that we did not review. Optimizing the position of the patient is an important prelude to uncomplicated laryngoscopy. Dr. Grabam identifies an additional intervention which may be useful to achieve a line of view to the larynx when optimal positioning alone does not. The effect of the manoeuvre cited is similar to that of laryngeal manipulation. He also introduces a second issue which has received little attention in the past. The poor quality light which be alludes to and compensates for with a second light source may not be due to his failing eyesight. The intensity of laryngo-pharyngeal illumination is influenced not only by the quality of the laryngoscope but also by the residual charge on the bandle batteries. As the battery charge is drained, the light output of the laryngoscope decreases exponentially. Also, as the laryngoscope itself ages and the light bundles deteriorate, new batteries are required almost continuously to provide even minimally acceptable light output and laryngo-pharyngeal illumination. Despite this, many laryngoscopes in use contain batteries with serious deficits in residual charge. In a survey of our own operating room, $70 \%$ of bandles contained batteries with residual charges so low as to compromise laryngoscope performance seriously. * Although it is possible that many of us have become proficient at working in the dark, it is a concern that such inadequate lighting may contribute to unanticipated difficulties during laryngoscopy. Dr. Graham's tips represent adjunct techniques to optimize direct laryngoscopy when unanticipated difficulties present.

Edward Crosby MD FRCPC

Mark Cleland*

Ottawa, Ontario

\section{Respiratory arrest following intrathe- cal sufentanil}

To the Editor:

I read with interest and concern the report by Katsiris et al., ${ }^{1}$ of respiratory arrest following intrathecal sufentanil in a parturient. It is important that the information in this report and in the other quoted cases change the way the technique is practiced:

1. In all cases, doses $\geq 10 \mu \mathrm{g}$ sufentanil were used. Intrathecal sufentanil is effective for labor analgesia in doses as small as $3 \mu \mathrm{g}^{2}$ particularly when used in combination with local anesthetics. In our practice, $5 \mu \mathrm{g}$ sufentanil plus $2.5 \mathrm{mg}$ hyperbaric bupivacaine $0.5 \%$ (final volume $1.5 \mathrm{ml}$ ) are very effective.

2. A $50 \mu \mathrm{g} \cdot \mathrm{ml}^{-1}$ commercial preparation of sufentanil is not the ideal "mother" solution for the $\mathrm{OB}$ setting. The $5 \mu \mathrm{g} \cdot \mathrm{ml}^{-1}$ solution, specially marketed for spinal/epidural use will reduce the risk of accidental overdose.

3. Unless administered in the lateral position, isobaric (hypobaric) bupivacaine ${ }^{3}$ and probably other solutions should not be used in the obstetric patient.

4. If the epidural catheter is to be tested after the intrathecal injection of sufentanil-bupivacaine, this should be done later. Even a small volume of a test dose will increase epidural pressure con- 